\title{
Tributyltin and Zebrafish: Swimming in Dangerous Water
}

\author{
Clemilson Berto-Júnior ${ }^{1,2}$, Denise Pires de Carvalho ${ }^{1,3,4}$, Paula Soares $^{5,6,7,8}$ and \\ Leandro Miranda-Alves ${ }^{1,3,9 *}$
}

\begin{abstract}
'Grupo de Pesquisa, Desenvolvimento e Inovação em Endocrinologia Experimental-GPDIEEx, Instituto de Ciências Biomédicas, Universidade Federal do Rio de Janeiro, Rio de Janeiro, Brazil, ${ }^{2}$ Laboratório Integrado de Ciências Farmacêuticas (LICFAR), Universidade Federal do Rio de Janeiro, Rio de Janeiro, Brazil, ${ }^{3}$ Endocrinologia, Faculdade de Medicina, Universidade Federal do Rio de Janeiro, Rio de Janeiro, Brazil, " ${ }^{4}$ Laboratório de Fisiologia Endócrina Doris Rosenthal, Instituto de Biofísica Carlos Chagas Filho, Universidade Federal do Rio de Janeiro, Rio de Janeiro, Brazil, ${ }^{5}$ Instituto de Investigação e Inovação em Saúde (i3S), Universidade do Porto, Porto, Portugal, ${ }^{6}$ Instituto de Patologia e Imunologia Molecular da Universidade do Porto (IPATIMUP) - Cancer Signaling and Metabolism, Porto, Portugal, ${ }^{7}$ Faculdade de Medicina, Universidade do Porto, Porto, Portugal, ${ }^{8}$ Departamento de Patologia, Faculdade de Medicina, Universidade do Porto, Porto, Portugal, ${ }^{9}$ Farmacologia e Química Medicinal, Instituto de Ciências Biomédicas, Universidade Federal do Rio de Janeiro, Rio de Janeiro, Brazil
\end{abstract}

\section{OPEN ACCESS}

Edited by: Wei Ge,

University of Macau, China

Reviewed by: Mingyu Li,

Xiamen University, China Peggy Biga,

University of Alabama at Birmingham, United States

Oliana Carnevali,

Università Politecnica delle Marche,

*Correspondence: Leandro Miranda-Alves alvesmpi@hotmail.com, Imalvesufrigmail.com

Specialty section: This article was submitted to Experimental Endocrinology,

a section of the journal

Frontiers in Endocrinology

Received: 16 December 2017 Accepted: 20 March 2018 Published: 10 April 2018

Citation:

Berto-Júnior $C$, de Carvalho DP, Soares P and Miranda-Alves L (2018) Tributyltin and Zebrafish: Swimming in Dangerous Water.

Front. Endocrinol. 9:152. doi: 10.3389/fendo.2018.00152
Zebrafish has been established as a reliable biological model with important insertion in academy (morphologic, biochemical, and pathophysiological studies) and pharmaceutical industry (toxicology and drug development) due to its molecular complexity and similar systems biology that recapitulate those from other organisms. Considering the toxicological aspects, many efforts using zebrafish models are being done in order to elucidate the effects of endocrine disruptors, and some of them are focused on tributyltin (TBT) and its mechanism of action. TBT is an antifouling agent applied in ship's hull that is constantly released into the water and absorbed by marine organisms, leading to bioaccumulation and biomagnification effects. Thus, several findings of malformations and changes in the normal biochemical and physiologic aspects of these marine animals have been related to TBT contamination. In the present review, we have compiled the most significant studies related to TBT effects in zebrafish, also taking into consideration the effects found in other study models.

Keywords: zebrafish, tributyltin, endocrine disruptors, imposex, obesogenic

\section{INTRODUCTION}

Zebrafish, Danio rerio, is a native teleost to the southeastern Himalayan region that has emerged as a reliable model for studying not only embryogenesis and regeneration, but also disease. The main advantages of zebrafish when compared to other biological models refer to their small size, the easy maintenance characteristics, and relatively low cost (1). Zebrafish has a high fertility rate that is characterized by dozens of embryos per matching couple, which allow a significant number of genetic approaches, such as morpholino antisense oligonucleotide technology to knock down several genes, study their function, and generate new disease models (2). Zebrafish has also been used in the field of drug discovery with great success, since it can be used for target identification, pharmacokinetic/pharmacodynamic, and toxicology studies (3). Due to its large and traditional use in the drug discovery field, the expertise of zebrafish model has been transferred to the analysis of endocrine disruptor effects. 
The anatomical structures are similar between zebrafish and human organs, which confirms that this model is versatile and useful. Compared to Caenorhabditis elegans and Drosophila melanogaster models, zebrafish has a greater number of genes with a higher homology to human genome (4). When it comes to Mus musculus comparison, zebrafish has about the same number of genes, although with less homology (70 versus 90\%) but with a lower annual cost (4). Menke and coworkers showed the anatomic and histologic features of adult zebrafish, evidencing similarity in the hematopoietic system, spleen, thymus, heart, thyroid, kidney, gastrointestinal system, liver, pancreas, brain (with telencephalon, diencephalons, mesencephalon, metencephalon, and myelencephalon), hypothalamus, pineal gland, pituitary gland, eye, and musculoskeletal system tissues, besides reproductive organs (5).

Therefore, the use of zebrafish for toxicology investigation comprises reproductive, developmental, neuro, cardiac, ocular, endocrine, vascular, and carcinogenic toxicity with several end points to be analyzed that should be chosen carefully for each purpose (6). Thus, the use of zebrafish for studying the effects of endocrine disruptors and/or their mechanism of action is convenient.

Endocrine-disrupting chemicals (EDCs) are natural occurring or synthetic compounds that interfere with natural hormone synthesis, secretion, transport, binding, or elimination, leading to homeostatic imbalance (7). Gore et al. (2014) postulated that EDC can enter the human body by different routes of exposition, such as oral consumption of contaminated food or water, contact with skin and/or inhalation, intravenous administration, and biological transfer through the placenta or milk during lactation (8).

As one of the most widespread EDC, tributyltin (TBT) has gained special attention. TBT is an organotin (one or more covalent bonds between carbon and tin atoms) that is used as an antifouling agent in boat paints and is continuously released into the water. As a result, harbor areas are deeply affected by this compound, which causes changes in the endocrine system of marine organisms, such as the development of male sexual anatomical characteristics in female gastropods, leading to sterility and death (9). TBT is rapidly absorbed by marine organisms, incorporated and accumulated in different tissues; after absorption, TBT can be metabolized and can generate other tin molecules, with different toxic properties and mechanisms of action (10).

The studies regarding TBT effects in zebrafish are rare compared to other species and EDC. Li and coworkers showed that the exposure of common carp to TBT for 7 days leads to oxidative stress, the inhibition of antioxidant enzymes, and the inhibition of the $\mathrm{Na}^{+} / \mathrm{K}^{+}$ATPase activity, acetylcholinesterase, and monoamine oxidase (11). Also, a diminished activity of $\mathrm{Na}^{+} / \mathrm{K}^{+}$ATPase was found in Sebastiscus marmoratus, which corroborates with the idea of a toxic effect of TBT (12).

\section{TBT, Gonads, and Sexual Bias}

Regarding sexual development, intraperitoneal injections of 1 or $5 \mathrm{mg} / \mathrm{kg}$ TBT in adult zebrafish lead to the reduction in mRNA levels of sox9 and Dax1 in brain, which is a conflicting result (13). TBT as a male-biased population agent usually causes a severe shift in organism end point toward masculinizing phenotype
(14). sox9 gene encodes a transcription factor related to the male phenotype, while Dax1 encodes a nuclear receptor that acts in the female development (15), so the presence of lower levels of sox9 in the brain, together with a male phenotype animal, shows how complex EDC treatment effects could be (Figure 1).

Tributyltin promotes a dose-dependent increase in the masculinization rate of embryos treated for 70 days from hatching, reaching almost $100 \%$ of sex rate toward male with the concentration of $100 \mathrm{ng} / \mathrm{L}$. These animals show abnormalities and a decreased motility of spermatozoid, because this population produces a higher quantity of spermatozoids that lack flagella (16). This is in agreement with other reports in the literature which suggest that TBT is an imposex-inducing agent in other species (17-23) and with the finding of aromatase inhibitory ability of TBT. Aromatase is the enzyme responsible for the conversion of androgens into estrogens in cells (Figure 2). Considering this, the human granulosa-like tumor cell line KGN displayed a significant suppressed aromatase activity when treated with TBT (24). Also, TBT might function as an agonist of the estrogen receptor alpha $(\mathrm{ER} \alpha)$, since it has a proliferative effect on ER (+) breast adenocarcinoma cell line (MCF-7) (25). The treatment of HeLa cells transiently co-transfected with zebrafish estrogen receptors (zfER $\alpha, z f E R \beta 1$, and $z f E R \beta 2)$ with ethinyl estradiol results in a fourfold to sixfold increase in luciferase activity, an effect that was inhibited by TBT. By contrast, when cells were co-transfected with zebrafish androgen receptor and treated with testosterone, the treatment with TBT was not able to change luciferase activity, showing that imposex-inducing ability of TBT is widely complex and multistep action (13).

\section{The Obesogenic Role of TBT}

Besides imposex, TBT is highly associated to increased adipogenesis and is considered as obesogenic (26). Little is known about TBT effects in brain, most of the studies being focused on

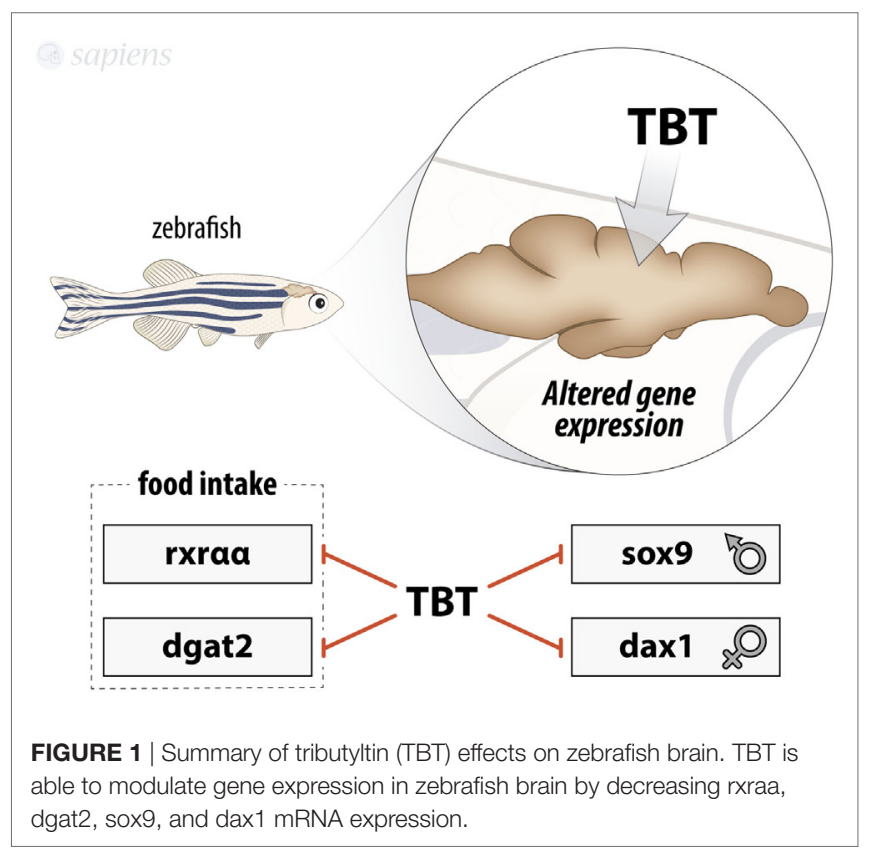



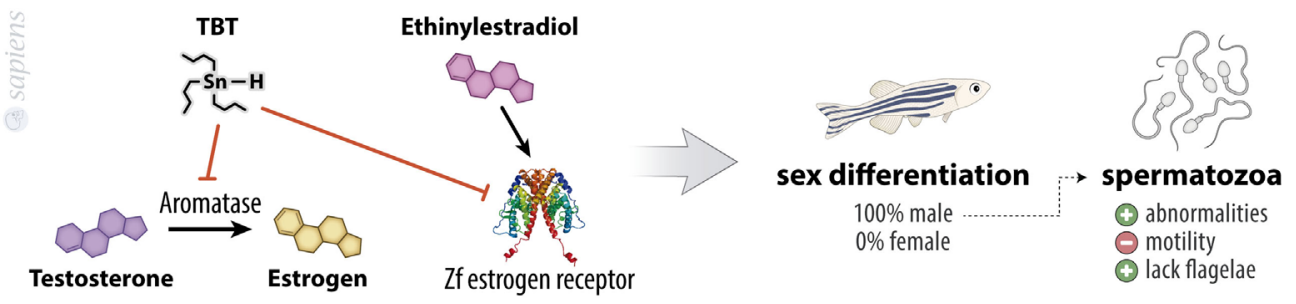

FIGURE 2 | Tribultytin (TBT) acting in sexual bias. TBT is an inhibitor of aromatase, the enzyme responsible for testosterone to estrogen conversion, besides inhibiting zebrafish estrogen receptor, decreasing the effects of ethinylestradiol. These molecular events point to male sexual differentiation of almost $100 \%$ of treated animals. TBT-treated animals also present increased spermatozoa abnormalities, increased lacking flagellae spermatozoa, and a decreased spermatozoa motility.

gene expression alterations concerning enzymes involved in lipid metabolism and sexual hormones $(13,27)$. Studies using 10 or $50 \mathrm{ng} / \mathrm{L}$ of TBT for 9 months in male and female animals showed the modulation of Retinoid X Receptor alpha $(\mathrm{RXR} \alpha / \alpha)$-nuclear receptor and DiacylGlycerol O-AcylTransferase 2 (DGAT2)lipogenic enzyme in both genders, with no modulation of PPAR $\gamma$ levels in brain, besides gender-specific alterations of gene expression (Figure 1). TBT might exert its lipogenic and adipocyte differentiation effects through the well-known RXR-PPAR $\gamma$ complex ligand ability $(28,29)$. These results confirm zebrafish as a good model for studying lipid homeostasis, since the complex mechanisms underlying food intake control and obesity development are similar to mammals.

The role of TBT as an obesogenic factor is well documented in the literature. Li and coworkers showed an activation of RXR-PPAR $\gamma$ heterodimer, triglyceride storage, and expression of adipogenic marker genes even in the presence of PPAR $\gamma$ agonist GW9662 in cultured preadipocytes (30). Indeed, TBT was shown to bind not only to RXR but also to PPAR $\gamma$ receptor (31), leading to weight gain, altered lipid homeostasis, lipid accumulation, raised expression of the adipocyte marker $\mathrm{C} / \mathrm{EBP} \alpha$, reduced adiponectin expression, altered glucose metabolism, increased PPAR $\gamma$ expression, and hepatic inflammation (32-34).

Zebrafish treated with TBT shows an increase in adipogenesis at 15 days post fertilization and displays significantly increased adipocyte differentiation markers, with altered gene expression profile of adipogenic factors, like POMC (hypothalamic factor involved in feed behavior) and leptin (35). These data are consistent with the findings showing that female rats treated with TBT for 15 days present hyperleptinemia (36).

Exposure to TBT in the nanomolar range for 3 days increases the percentage of adiposity in larvae (by Nile red staining of adipocyte lipid droplets) with the induction of adipocyte hypertrophy despite fasting (37). Interestingly, human PPAR $\gamma$ antagonists did not block the in vivo obesogenic effect of TBT, but the human RXR antagonist UVI3003 fully abolished the effect, confirming that zebrafish adipose tissue is readily responsive to adipogenic molecules, even in a fasting state via RXR pathway (38). Zebrafish exposed to TBT for 9 months also presented altered body weight with increased triglycerides in male and the modulation of a range of lipogenic genes in liver, such as $\operatorname{PPAR} \gamma, \mathrm{RXR} \alpha, \mathrm{C} / \mathrm{EBP} \beta$, and IGFII $\alpha$, all of them being adipogenic stimulators (27). Some recent work fully ratifies not only the zebrafish as an animal model for adipose tissue studies but also points to new techniques for assaying adipocytes dynamics in zebrafish (39-41) (Figure 3).

It was also reported that TBT could affect nutritional status by modifying yolk absorption. Yolk provides energy and nutrients for developmental phases in teleosts, since it is mainly composed of phospholipids and triacylglycerols packed into lipoprotein particles (vitellogenin) and surrounded by the yolk syncytial layer that functions to hydrolyze yolk molecules and transport them to embryos. TBT, as an obesogenic agent, causes a faster uptake of yolk (42).

\section{Other TBT Effects in Zebrafish}

Regarding behavioral aspects, there are only few studies and most of them point to altered end points. Male Wistar rats treated with various doses of TBT showed a dose-dependent decrease in spontaneous motor activity during dark phase and an inhibition in the acquisition of shock avoidance responses also in a dosedependent manner, indicating that TBT exposure can cause a significant disturbance in rat behavior (43). Non-reproductive behavior alteration in teleost rare minnow was also documented, revealing that fish exposed to TBT had less group cohesion during the course of a $10 \mathrm{~min}$ period of observation, altered shoaling in novel tank test, shorter latency before leaving shoal mates, and they spent more time away from shoal than control fish, with increased anxiety (44).

Considering the antioxidant ability and immunity, an 8-week treatment with TBT reduced superoxide dismutase (SOD), catalase (CAT), and glutathione peroxidase (GPX) activities in a dose-dependent manner, with an increase in the relative expression of HSP70 and HSP90, IL- $1 \beta$, IL-6, TNF- $\alpha$, and NF- $\kappa$ B. Thus, TBT is an inducer of oxidative stress and plays an important role in the positive modulation of pro-inflammatory cytokines (45). This is consistent with data showing a decreased activity of SOD, CAT, and GPX in other species $(46,47)$, a higher expression of HSP70 in common carp (48), an increased IL-1 $\beta$ secretion by human immune cells (49), an increased IL-6 production in human peripheral blood mononuclear cells (50), and higher TNF- $\alpha$ levels in mouse serum (51).

It was also reported that TBT could affect nutritional status by modifying yolk absorption. Yolk in teleosts provides energy and nutrients for the developmental phase, being composed in majority of phospholipids and triacylglycerols packed into lipoprotein particles (vitellogenin) and surrounded by the yolk syncytial layer 


\section{sapiens}
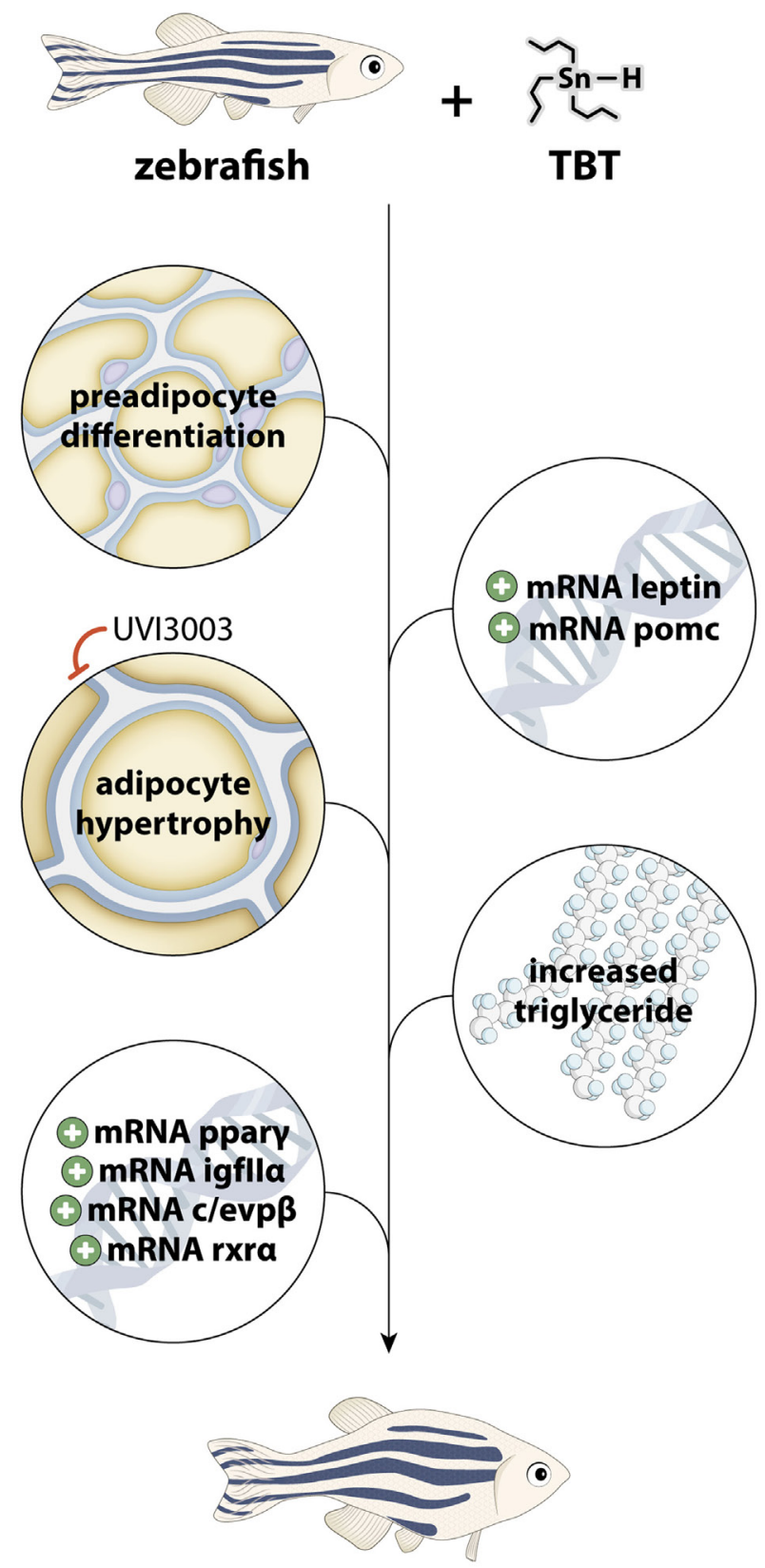

\section{obese zebrafish}

FIGURE 3 | Tributyltin (TBT) as obesogenic molecule. TBT-treated zebrafish presents increased preadipocytes differentiation, modulation of pomc, leptin, ppar $\gamma, \mathrm{c} / \operatorname{evp} \beta$, IGFIl $\alpha$, and rxr $\alpha \mathrm{mRNA}$, increased adipocyte hypertrophy (that can be blocked by UVI3003) and increased triglyceride levels, culminating in an obese animal.

that functions hydrolyzing yolk molecules and transporting them to embryo. TBT, as obesogenic agent, caused a faster uptake of yolk in an automatic method to segment and quantify yolk areas in zebrafish larvae (42).
Zebrafish larvae treated with TBT $(0.03 \mathrm{nM})$ show increased death with diminished hatch rates, an abnormal body curvature, a higher pericardial edema, and a dorsal curve rate. These data are controversial since Liang and coworkers (52) showed a higher hatch rate in embryos treated with higher concentrations of TBT (1 nM). Nevertheless, this could be due to EDC dose-response behavior that often show nonmonotonic dose-response curve in a U-shaped or inverted $\mathrm{U}$-shaped curves $(0.03$ or $1 \mathrm{nM})$, probably belonging to any point of the curve with a hatch rate as end point (53). Also, a decrease in heart rate was reported, with the differential expression of important genes related to cardiac function and development, such as cav3 that encodes caveolin 3 protein and cmlc1, which encodes cardiac myosin light chain-1 (essential for zebrafish cardiogenesis) $(54,55)$. Other studies concerning cardiac function in TBT-treated animals were published revealing that this organotin induces cardiomyopathy in clam Ruditapes (56) and increased collagen deposition in heart interstice, impaired coronary vascular reactivity to estradiol, and enhanced the number of mast cells proximate to cardiac vessels in rats (57).

Unprecedented studies in zebrafish assessing TBT effects in systems not widely rummaged are also available. TUNEL staining of zebrafish embryos displayed TBT-induced apoptosis restricted to retinal neuronal cells and unidentified cells around trigeminal neurons with macrophage accumulation, probably by higher accumulation of TBT in the optic tract (58), showing selective apoptosis in this tissue (59). Also, genotoxicity using zebrafish erythrocytes was reported in an erythrocytic nuclear abnormality (ENA) frequency assay in animals exposed for 4 months, exhibiting a higher ENA frequency in TBT-treated conditions (60).

\section{CONCLUSION}

Studies concerning TBT as an EDC are rapidly growing every year based on its wide range of effects in humans and laboratory animals. These broad options of models comprising normal systems and diseases are of great importance for recognizing TBT actions due to its widespread usage in the world. Zebrafish is a reliable model for studying several diseases like cancer, obesity, and inflammation and has become a robust tool for assessing EDC effects. Studies using zebrafish as a biological model to access TBT effects are few but they corroborate the effects found in other classical animal models, such as murine ones. Brain effects of TBT related to behavior changes are well documented in the literature $(44,61-64)$ and absent in zebrafish, even though these animals possess similar structures and molecular complexity comparable to other models in order to test memory, anxiety, fear, and social behavior (65-67). Also, considering the hypothalamus-pituitary-thyroid axis, no study has been done yet to evaluate the effects of this compound in zebrafish, although an extensive and elucidating review described the action of TBT in other species (68).

\section{AUTHOR CONTRIBUTIONS}

CB-J, DC, PS, and LM-A conceived and wrote the article. 


\section{FUNDING}

This study was supported by Fundação Carlos Chagas Filho de Amparo à Pesquisa do Estado do Rio de Janeiro (PP-SUSFAPERJ E-26/110.282/2014; JCNE-FAPERJ, E-26/201.520/ 2014; APQ1-FAPERJ, E-26/111.485/2014), Coordenação de Aperfeiçoamento de Pessoal de Nível Superior (CAPES/ Ciências sem Fronteiras/Pesquisador Visitante Especial/88881. 062218/2014-0), and Conselho Nacional de Desenvolvimento Científico (CNPq, PQ- Nível 2, 305872/2016-8). Funding was obtained from FEDER-Fundo Europeu de Desenvolvimento Regional funds through the COMPETE 2020-Operacional

\section{REFERENCES}

1. Scholz S, Mayer I. Molecular biomarkers of endocrine disruption in small model fish. Mol Cell Endocrinol (2008) 293(1-2):57-70. doi:10.1016/j. mce.2008.06.008

2. Tavares B, Santos Lopes $\mathrm{S}$. The importance of zebrafish in biomedical research. Acta Med Port (2013) 26(5):583-92.

3. Das BC, McCormick L, Thapa P, Karki R, Evans T. Use of zebrafish in chemical biology and drug discovery. Future Med Chem (2013) 5(17):2103-16. doi:10.4155/fmc. 13.170

4. Williams $\mathrm{CH}$, Hong CC. Multi-step usage of in vivo models during rational drug design and discovery. Int J Mol Sci (2011) 12(4):2262-74. doi:10.3390/ ijms12042262

5. Menke AL, Spitsbergen JM, Wolterbeek APM, Woutersen RA. Normal anatomy and histology of the adult zebrafish. Toxicol Pathol (2011) 39(5):759-75. doi:10.1177/0192623311409597

6. Hill AJ, Teraoka H, Heideman W, Peterson RE. Zebrafish as a model vertebrate for investigating chemical toxicity. Toxicol Sci (2005) 86(1):6-19. doi:10.1093/ toxsci/kfil10

7. Kabir ER, Rahman MS, Rahman I. A review on endocrine disruptors and their possible impacts on human health. Environ Toxicol Pharmacol (2015) 40(1):241-58. doi:10.1016/j.etap.2015.06.009

8. Introduction to Endocrine Disrupting Chemicals.pdf [Internet] (2014). [cited 2017 Oct 12]. Available from: http://www.endocrine.org/ /media/endosociety/Files/Advocacy\%20and\%20Outreach/Important\%20Documents/ Introduction\%20to\%20Endocrine\%20Disrupting\%20Chemicals.pdf

9. de Carvalho Oliveira R, Santelli RE. Occurrence and chemical speciation analysis of organotin compounds in the environment: a review. Talanta (2010) 82(1):9-24. doi:10.1016/j.talanta.2010.04.046

10. Antizar-Ladislao B. Environmental levels, toxicity and human exposure to tributyltin (TBT)-contaminated marine environment. A review. Environ Int (2008) 34(2):292-308. doi:10.1016/j.envint.2007.09.005

11. Li Z-H, Li P, Shi Z-C. Physiological and molecular responses in brain of juvenile common carp (Cyprinus carpio) following exposure to tributyltin. Environ Toxicol (2016) 31(3):278-84. doi:10.1002/tox.22042

12. Zhang J, Zuo Z, Chen R, Chen Y, Wang C. Tributyltin exposure causes brain damage in Sebastiscus marmoratus. Chemosphere (2008) 73(3):337-43. doi:10.1016/j.chemosphere.2008.05.072

13. McGinnis CL, Crivello JF. Elucidating the mechanism of action of tributyltin (TBT) in zebrafish. Aquat Toxicol (2011) 103(1-2):25-31. doi:10.1016/j. aquatox.2011.01.005

14. Santos D, Luzio A, Coimbra AM. Zebrafish sex differentiation and gonad development: a review on the impact of environmental factors. Aquat Toxicol (2017) 191:141-63. doi:10.1016/j.aquatox.2017.08.005

15. von Hofsten J, Olsson PE. Zebrafish sex determination and differentiation: involvement of FTZ-F1 genes. Reprod Biol Endocrinol (2005) 3:63. doi:10.1186/1477-7827-3-63

16. McAllister BG, Kime DE. Early life exposure to environmental levels of the aromatase inhibitor tributyltin causes masculinisation and irreversible sperm damage in zebrafish (Danio rerio). Aquat Toxicol (2003) 65(3):309-16. doi:10.1016/S0166-445X(03)00154-1
Programme for Competitiveness and Internationalization (POCI), Portugal 2020, and by Portuguese funds through FCT-Fundação para a Ciência e a Tecnologia/Ministério da Ciência, Tecnologia e Inovação in the framework of the project "Institute for Research and Innovation in Health Sciences" (POCI-01-0145-FEDER-007274) and by the project "Advancing cancer research: from basic knowledgement to application"; NORTE-01-0145-FEDER-000029; Projetos Estruturados de I\&D\&I, funded by Norte 2020-Programa Operacional Regional do Norte. The funders had no role in the study design, data collection and analysis, decision to publish, or preparation of the manuscript.

17. Artifon V, Castro ÍB, Fillmann G. Spatiotemporal appraisal of TBT contamination and imposex along a tropical bay (Todos os Santos Bay, Brazil). Environ Sci Pollut Res Int (2016) 23(16):16047-55. doi:10.1007/s11356-0166745-7

18. Batista RM, Castro IB, Fillmann G. Imposex and butyltin contamination still evident in Chile after TBT global ban. Sci Total Environ (2016)566-567: 446-53. doi:10.1016/j.scitotenv.2016.05.039

19. Kim NS, Hong SH, Shin K-H, Shim WJ. Imposex in Reishia clavigera as an indicator to assess recovery of TBT pollution after a total ban in South Korea. Arch Environ Contam Toxicol (2017) 73(2):301-9. doi:10.1007/ s00244-017-0369-x

20. Laranjeiro F, Sánchez-Marín P, Oliveira IB, Galante-Oliveira S, Barroso C. Fifteen years of imposex and tributyltin pollution monitoring along the Portuguese coast. Environ Pollut (2018) 232:411-21. doi:10.1016/j. envpol.2017.09.056

21. Ruiz JM, Carro B, Albaina N, Couceiro L, Míguez A, Quintela M, et al. Bi-species imposex monitoring in Galicia (NW Spain) shows contrasting achievement of the OSPAR ecological quality Objective for TBT. Mar Pollut Bull (2017) 114(2):715-23. doi:10.1016/j.marpolbul.2016.10.058

22. Wells FE, Keesing JK, Brearley A. Recovery of marine Conus (Mollusca: Caenogastropoda) from imposex at Rottnest Island, Western Australia, over a quarter of a century. Mar Pollut Bull (2017) 123:182-7. doi:10.1016/j. marpolbul.2017.08.064

23. Zeidan GC, Boehs G. Assessment of tributyltin contamination based on imposex in Stramonita rustica (Mollusca: Gastropoda) along southern Bahia coast, northeastern Brazil. Braz J Biol (2017) 77(1):185-90. doi:10.1590/1519-6984.15115

24. Saitoh M, Yanase T, Morinaga H, Tanabe M, Mu YM, Nishi Y, et al. Tributyltin or triphenyltin inhibits aromatase activity in the human granulosa-like tumor cell line KGN. Biochem Biophys Res Commun (2001) 289(1):198-204. doi:10.1006/bbrc.2001.5952

25. Sharan S, Nikhil K, Roy P. Effects of low dose treatment of tributyltin on the regulation of estrogen receptor functions in MCF-7 cells. Toxicol Appl Pharmacol (2013) 269(2):176-86. doi:10.1016/j.taap.2013.03.009

26. Grün F. The obesogen tributyltin. Vitam Horm (2014) 94:277-325. doi:10.1016/ B978-0-12-800095-3.00011-0

27. Lyssimachou A, Santos JG, André A, Soares J, Lima D, Guimarães L, et al. The Mammalian "Obesogen" tributyltin targets hepatic triglyceride accumulation and the transcriptional regulation of lipid metabolism in the liver and brain of zebrafish. PLoS One (2015) 10(12):e0143911. doi:10.1371/journal. pone.0143911

28. Kanayama T, Kobayashi N, Mamiya S, Nakanishi T, Nishikawa J. Organotin compounds promote adipocyte differentiation as agonists of the peroxisome proliferator-activated receptor gamma/retinoid X receptor pathway. $\mathrm{Mol}$ Pharmacol (2005) 67(3):766-74. doi:10.1124/mol.104.008409

29. le Maire A, Grimaldi M, Roecklin D, Dagnino S, Vivat-Hannah V, Balaguer $\mathrm{P}$, et al. Activation of RXR-PPAR heterodimers by organotin environmental endocrine disruptors. EMBO Rep (2009) 10(4):367-73. doi:10.1038/ embor. 2009.8

30. Li X, Ycaza J, Blumberg B. The environmental obesogen tributyltin chloride acts via peroxisome proliferator activated receptor gamma to induce 
adipogenesis in murine 3T3-L1 preadipocytes. J Steroid Biochem Mol Biol (2011) 127(1-2):9-15. doi:10.1016/j.jsbmb.2011.03.012

31. Grün F, Watanabe H, Zamanian Z, Maeda L, Arima K, Cubacha R, et al. Endocrine-disrupting organotin compounds are potent inducers of adipogenesis in vertebrates. Mol Endocrinol (2006) 20(9):2141-55. doi:10.1210/ me.2005-0367

32. Muscogiuri G, Barrea L, Laudisio D, Savastano S, Colao A. Obesogenic endocrine disruptors and obesity: myths and truths. Arch Toxicol (2017) 91:3469-75. doi:10.1007/s00204-017-2071-1

33. Regnier SM, El-Hashani E, Kamau W, Zhang X, Massad NL, Sargis RM. Tributyltin differentially promotes development of a phenotypically distinct adipocyte. Obesity (Silver Spring) (2015) 23(9):1864-71. doi:10.1002/ oby. 21174

34. Bertuloso BD, Podratz PL, Merlo E, de Araújo JFP, Lima LCF, de Miguel EC, et al. Tributyltin chloride leads to adiposity and impairs metabolic functions in the rat liver and pancreas. Toxicol Lett (2015) 235(1):45-59. doi:10.1016/j. toxlet.2015.03.009

35. den Broeder MJ, Moester MJB, Kamstra JH, Cenijn PH, Davidoiu V, Kamminga LM, et al. Altered adipogenesis in zebrafish larvae following high fat diet and chemical exposure is visualised by stimulated Raman scattering microscopy. Int J Mol Sci (2017) 18(4):894. doi:10.3390/ijms18040894

36. Sena GC, Freitas-Lima LC, Merlo E, Podratz PL, de Araújo JFP, Brandão PAA, et al. Environmental obesogen tributyltin chloride leads to abnormal hypothalamic-pituitary-gonadal axis function by disruption in kisspeptin/ leptin signaling in female rats. Toxicol Appl Pharmacol (2017) 319:22-38. doi:10.1016/j.taap.2017.01.021

37. Tingaud-Sequeira A, Ouadah N, Babin PJ. Zebrafish obesogenic test: a tool for screening molecules that target adiposity. J Lipid Res (2011) 52(9):1765-72. doi:10.1194/jlr.D017012

38. Ouadah-Boussouf N, Babin PJ. Pharmacological evaluation of the mechanisms involved in increased adiposity in zebrafish triggered by the environmental contaminant tributyltin. Toxicol Appl Pharmacol (2016) 294:32-42. doi:10.1016/j.taap.2016.01.014

39. Minchin JEN, Rawls JF. A classification system for zebrafish adipose tissues. Dis Model Mech (2017) 10(6):797-809. doi:10.1242/dmm.025759

40. Minchin JEN, Rawls JF. In vivo imaging and quantification of regional adiposity in zebrafish. Methods Cell Biol (2017) 138:3-27. doi:10.1016/ bs.mcb.2016.11.010

41. Minchin JEN, Rawls JF. In vivo analysis of white adipose tissue in zebrafish. Methods Cell Biol (2011) 105:63-86. doi:10.1016/B978-0-12-381320-6.00003-5

42. Kalasekar SM, Zacharia E, Kessler N, Ducharme NA, Gustafsson JÅ, Kakadiaris IA, et al. Identification of environmental chemicals that induce yolk malabsorption in zebrafish using automated image segmentation. Reprod Toxicol (2015) 55:20-9. doi:10.1016/j.reprotox.2014.10.022

43. Ema M, Itami T, Kawasaki H. Behavioral effects of acute exposure to tributyltin chloride in rats. Neurotoxicol Teratol (1991) 13(5):489-93. doi:10.1016/0892-0362(91)90054-Z

44. Zhang J, Zhang C, Sun P, Shao X. Tributyltin affects shoaling and anxiety behavior in female rare minnow (Gobiocypris rarus). Aquat Toxicol (2016) 178:80-7. doi:10.1016/j.aquatox.2016.07.007

45. Zhang C-N, Zhang J-L, Ren H-T, Zhou B-H, Wu Q-J, Sun P. Effect of tributyltin on antioxidant ability and immune responses of zebrafish (Danio rerio). Ecotoxicol Environ Saf (2017) 138:1-8. doi:10.1016/j.ecoenv.2016. 12.016

46. Kanimozhi V, Palanivel K, Akbarsha MA, Kadalmani B. Tributyltin-mediated hepatic, renal and testicular tissue damage in male Syrian hamster (Mesocricetus auratus): a study on impact of oxidative stress. Springerplus (2016) 5(1):1523. doi:10.1186/s40064-016-3186-1

47. Zhou J, Zhu X, Cai Z. Tributyltin toxicity in abalone (Haliotis diversicolor supertexta) assessed by antioxidant enzyme activity, metabolic response, and histopathology. J Hazard Mater (2010) 183(1-3):428-33. doi:10.1016/j. jhazmat.2010.07.042

48. Li ZH, Li P, Shi ZC. Chronic effects of tributyltin on multiple biomarkers responses in juvenile common carp, Cyprinus carpio. Environ Toxicol (2016) 31(8):937-44. doi:10.1002/tox.22103

49. Brown S, Whalen M. Tributyltin alters secretion of interleukin 1 beta from human immune cells. J Appl Toxicol (2015) 35(8):895-908. doi:10.1002/ jat.3087
50. Brown S, Wilburn W, Martin T, Whalen M. Butyltin compounds alter secretion of interleukin 6 from human immune cells. J Appl Toxicol (2018) 38(2):201-18. doi:10.1002/jat.3514

51. Lawrence S, Pellom ST, Shanker A, Whalen MM. Tributyltin exposure alters cytokine levels in mouse serum. J Immunotoxicol (2016) 13(6):870-8. doi:10. 1080/1547691X.2016.1221867

52. Liang X, Souders CL, Zhang J, Martyniuk CJ. Tributyltin induces premature hatching and reduces locomotor activity in zebrafish (Danio rerio) embryos/ larvae at environmentally relevant levels. Chemosphere (2017) 189:498-506. doi:10.1016/j.chemosphere.2017.09.093

53. Vandenberg LN, Colborn T, Hayes TB, Heindel JJ, Jacobs DR, Lee D-H, et al. Hormones and endocrine-disrupting chemicals: low-dose effects and nonmonotonic dose responses. Endocr Rev (2012) 33(3):378-455. doi:10.1210/ er.2011-1050

54. Chen Z, Huang W, Dahme T, Rottbauer W, Ackerman MJ, Xu X. Depletion of zebrafish essential and regulatory myosin light chains reduces cardiac function through distinct mechanisms. Cardiovasc Res (2008) 79(1):97-108. doi:10.1093/cvr/cvn073

55. Huang L, Zuo Z, Zhang Y, Wang C. Toxicogenomic analysis in the combined effect of tributyltin and benzo[a]pyrene on the development of zebrafish embryos. Aquat Toxicol (2015) 158:157-64. doi:10.1016/j.aquatox.2014. 10.024

56. Hanana H, Simon G, Kervarec N, Cérantola S. Evaluation of toxicological effects induced by tributyltin in clam Ruditapes decussatus using high-resolution magic angle spinning nuclear magnetic resonance spectroscopy: study of metabolic responses in heart tissue and detection of a novel metabolite. Toxicol Rep (2014) 1:777-86. doi:10.1016/j.toxrep.2014.09.012

57. dos Santos RL, Podratz PL, Sena GC, Filho VSD, Lopes PFI, Gonçalves WLS, et al. Tributyltin impairs the coronary vasodilation induced by $17 \beta$-estradiol in isolated rat heart. J Toxicol Environ Health A (2012) 75(16-17):948-59. doi:10.1080/15287394.2012.695231

58. Rouleau C, Xiong Z-H, Pacepavicius G, Huang G-L. Uptake of waterborne tributyltin in the brain of fish: axonal transport as a proposed mechanism. Environ Sci Technol (2003) 37(15):3298-302. doi:10.1021/ es $020984 \mathrm{n}$

59. Dong W, Muramoto W, Nagai Y, Takehana K, Stegeman JJ, Teraoka H, et al. Retinal neuronal cell is a toxicological target of tributyltin in developing zebrafish. J Vet Med Sci (2006) 68(6):573-9. doi:10.1292/jvms.68.573

60. Micael J, Reis-Henriques MA, Carvalho AP, Santos MM. Genotoxic effects of binary mixtures of xenoandrogens (tributyltin, triphenyltin) and a xenoestrogen (ethinylestradiol) in a partial life-cycle test with zebrafish (Danio rerio). Environ Int (2007) 33(8):1035-9. doi:10.1016/j.envint.2007.06.004

61. Huchim-Lara O, Salas S, Chin W, Montero J, Fraga J. Diving behavior and fishing performance: the case of lobster artisanal fishermen of the Yucatan coast, Mexico. Undersea Hyperb Med (2015) 42(4):285-96.

62. Li Z-H, Li P. Evaluation of tributyltin toxicity in Chinese rare minnow larvae by abnormal behavior, energy metabolism and endoplasmic reticulum stress. Chem Biol Interact (2015) 227:32-6. doi:10.1016/j.cbi.2014.12.010

63. Si J, Li J, Zhang F, Li G, Xin Q, Dai B. Effects of perinatal exposure to low doses of tributyltin chloride on pregnancy outcome and postnatal development in mouse offspring. Environ Toxicol (2012) 27(10):605-12. doi:10.1002/tox. 20753

64. Frye CA, Bo E, Calamandrei G, Calzà L, Dessì-Fulgheri F, Fernández M, et al. Endocrine disrupters: a review of some sources, effects, and mechanisms of actions on behaviour and neuroendocrine systems. J Neuroendocrinol (2012) 24(1):144-59. doi:10.1111/j.1365-2826.2011.02229.x

65. Li X, Sun M-Z, Li X, Zhang S-H, Dai L-T, Liu X-Y, et al. Impact of low-dose chronic exposure to bisphenol A (BPA) on adult male zebrafish adaption to the environmental complexity: disturbing the color preference patterns and reliving the anxiety behavior. Chemosphere (2017) 186:295-304. doi:10.1016/j. chemosphere.2017.07.164

66. Matsuda K, Yoshida M, Kawakami K, Hibi M, Shimizu T. Granule cells control recovery from classical conditioned fear responses in the zebrafish cerebellum. Sci Rep (2017) 7(1):11865. doi:10.1038/s41598-017-10794-0

67. Shams S, Amlani S, Buske C, Chatterjee D, Gerlai R. Developmental social isolation affects adult behavior, social interaction, and dopamine metabolite levels in zebrafish. Dev Psychobiol (2018) 60(1):43-56. doi:10.1002/dev. 21581 
68. Santos-Silva AP, Andrade MN, Pereira-Rodrigues P, Paiva-Melo FD, Soares P, Graceli JB, et al. Frontiers in endocrine disruption: impacts of organotin on the hypothalamus-pituitary-thyroid axis. Mol Cell Endocrinol (2018) 460:246-57. doi:10.1016/j.mce.2017.07.038

Conflict of Interest Statement: The authors declare that the research was conducted in the absence of any commercial or financial relationships that could be construed as a potential conflict of interest.
Copyright (c) 2018 Berto-Júnior, de Carvalho, Soares and Miranda-Alves. This is an open-access article distributed under the terms of the Creative Commons Attribution License (CC BY). The use, distribution or reproduction in other forums is permitted, provided the original author(s) and the copyright owner are credited and that the original publication in this journal is cited, in accordance with accepted academic practice. No use, distribution or reproduction is permitted which does not comply with these terms. 